\title{
REDUÇÃO DAS IRREGULARIDADES IDENTIFICADAS NA APLICAÇÃO DO FMEA DE PROCESSO: UM ESTUDO EM PRODUTOS ESTAMPADOS
}

\section{THE REDUCTION OF IRREGULARITIES IN THE USE OF "PROCESS FMEA": A STUDY FOR A COLD STAMPING PROCESS}

\author{
Carla Estorilio*E-mail: amodio@utfpr.edu.br \\ Richard Posso*E-mail: rposso@pop.com.br \\ * Universidade Tecnológica Federal do Paraná - UTFPR, Curitiba, PR
}

\begin{abstract}
Resumo: A Análise do Modo e Efeito da Falha (FMEA, Failure Mode and Effect Analysis) é um dos requisitos exigidos pela ISO/TS 16949. Entretanto, pesquisas mostram irregularidades no seu desenvolvimento, por parte dos fornecedores das automotivas. O objetivo desse estudo é identificar essas irregularidades, visando sugerir meios para minimizar esse problema. Para isso, questionários foram aplicados em sete fornecedores de uma empresa automotiva, incluindo a análise de dez FMEA's de cada um deles. $O$ trabalho identifica as irregularidades no desenvolvimento do FMEA para um processo de estampagem e ressalta sete fatores que contribuem para que elas aconteçam. Baseado nesses dados, uma estratégia é sugerida, a qual inclui uma planilha de FMEA parcialmente parametrizada, a qual é testada em três destes fornecedores, mostrando uma melhoria significativa.
\end{abstract}

Palavras-chave: FMEA. Qualidade. Confiabilidade. Falha.

Abstract: The Failure Mode and Effect Analysis (FMEA) is a requirement for ISO/TS 16949. However, researches show nonconformities in its use by automotive suppliers. The objective of this study is to identify these nonconformities, aiming to suggest methods for minimizing this problem. Therefore, questionnaires were applied in seven automotive suppliers and, for each one, ten FMEA's were analysed. The research identified nonconformities in the use of FMEA for the stamping process and highlighted seven influencing factors. Based on this data, a strategy is suggested. A partially parameterised FMEA spreadsheet is suggested and tested in three suppliers, showing significant improvements.

Keywords: FMEA. Quality. Reliability. Failure.

\section{INTRODUÇÃO}

A satisfação do cliente pode ser expressa pela relação entre percepção e expectativa (Almeida, 2003). Nesse contexto, a confiabilidade tem se tornado cada vez mais importante para os consumidores. Segundo Biasoli (2003), a falha de um produto no período de garantia implica em custos para a empresa, além de comprometer a credibilidade do cliente. 
Além do custo, a segurança é fundamental, pois a tecnologia pode colocar produtos perigosos nas mãos de amadores, além de criar subprodutos que podem ameaçar a saúde, a segurança e o meio ambiente (Juran, 1997).

$\mathrm{Na}$ fase de projeto, uma das técnicas mais utilizadas e difundidas para melhorar a confiabilidade de um produto é o FMEA (Ferreira e Toledo, 2001; Nogueira e Toledo, 1999). Esse método permite a análise preventiva das possíveis causas das falhas. Dessa maneira, é reduzida a possibilidade de um defeito ocorrer, melhorando, assim, a confiabilidade do produto.

Nos últimos anos, muitas organizações têm usado o FMEA, em particular, as automotivas. Isso vem ocorrendo em função da QS-9000 (Quality System), a qual determina o uso deste método pelas automotivas e seus fornecedores durante o projeto e desenvolvimento de novos produtos ou processos (IQA, 2002; IQA, 1998).

A ISO/TS 16949 (Norma Automotiva Mundial), que equivale à QS-9000, é uma norma elaborada por um grupo de fabricantes automotivos e suas respectivas associações, a qual visa definir os requisitos de qualidade dos fornecedores internos ou externos.

Entretanto, a aplicação do FMEA ainda é questionada por muitas organizações. Segundo Tumer et al. (2003), o FMEA é considerado trabalhoso e de alto custo em termos econômicos e em relação ao tempo despendido. Além disso, muitas aplicações têm apresentado resultados insatisfatórios devido às descrições inconsistentes das funções do objeto estudado e de suas respectivas falhas.

Entretanto, o aumento da importância das métricas de confiabilidade vem de encontro com os métodos de predição, especialmente os utilizados em novos projetos.

Aguiar e Salomon (2007) analisaram formulários de FMEA de onze empresas da cadeia automotiva e constataram irregularidades na sua aplicação, priorizando-as quanto à gravidade de sua ocorrência. Como resultado, eles rejeitaram três FMEA's em função do nível de irregularidade. Para eles, esse fenômeno ocorre em função dos fornecedores de primeiro nível atuarem como se fossem montadoras, delegando parte da sua produção para empresas menores. Essas empresas, que normalmente atuam em outras cadeias produtivas, encontram dificuldades em se enquadrar nas exigências de qualidade impostas pelo segmento automotivo.

Revista Produção Online. Florianópolis, SC, v.11, n. 4, p. 995-1027, out./dez. 2011. 
Segundo CEV (2005), apesar das inúmeras publicações e ações realizadas, a maior parte das organizações não tem conseguido aproveitar os benefícios que o FMEA disponibiliza. Através de uma pesquisa em mais de uma centena de empresas, concluiu-se que a maior parte delas não vê o FMEA como um método de grande potencial, mas sim, como algo necessário para cumprir os requisitos das auditorias da qualidade ou as especificações dos clientes.

Considerando as exigências do setor automotivo quanto à gestão da qualidade e o fato do FMEA ser um pré-requisito nesse contexto, julga-se importante a realização de estudos que contribuam para explicitar e minimizar as discrepâncias encontradas no preenchimento de seus formulários.

Sendo assim, esse estudo analisa o desenvolvimento do FMEA de Processo, realizado por uma montadora de veículos e sete de seus principais fornecedores. $O$ objetivo é identificar as irregularidades que ocorrem durante o preenchimento da planilha e desenvolver uma estratégia para reduzir essas discrepâncias. Para isso, investiga os fatores de influência que acabam gerando as disparidades nas análises de FMEA e os detalhes envolvidos no preenchimento do método.

\section{MÉTODO DE PESQUISA}

O método de pesquisa adotado é o estudo de caso, conforme Yin (2001), em função de se investigar um fenômeno contemporâneo dentro de seu contexto real, buscando saber como e por que esse fenômeno ocorre.

O campo de estudo é uma montadora de veículos situada no Paraná, incluindo sete de seus principais fornecedores de peças estampadas. Estes sete representam o maior volume no fornecimento de peças, contabilizando 327 peças de um total de 357. A pesquisa é desenvolvida em três etapas descritas a seguir:

1. Identificação dos fatores de influência - para o desenvolvimento dessa fase foi utilizada a pesquisa bibliográfica e a coleta de dados junto àqueles que preenchem os FMEA's. Essa coleta ocorreu através de um questionário, além de considerar a análise de dez FMEA's de processo de cada fornecedor, realizados durante vinte e quatro meses (2008 e 2009). 
2. Proposição de melhorias - os dados coletados foram analisados, dando origem a uma estratégia para o preenchimento do FMEA, que envolveu uma planilha parcialmente parametrizada;

3. Validação da estratégia - foi selecionada uma peça estampada para que seu processo de fabricação fosse analisado pelos fornecedores com a nova planilha. Essa peça foi escolhida por envolver no máximo três operações de estampagem, ser de média complexidade geométrica e se encontrar em processo de nacionalização e orçamento por parte de três dos sete fornecedores estudados. Sendo assim, apenas esses três participaram da validação da estratégia, os quais eram de portes diferentes: pequeno, médio e grande porte. Essa variação contribuiu para identificar se haviam impactos em função do tamanho da empresa. Ao final, os três FMEA's foram analisados e, posteriormente, o nível de divergência destes foi comparado com o nível de divergência dos anteriormente coletados.

\section{QUALIDADE, CONFIABILIDADE E FALHA}

Considerando que o tema desse trabalho é o FMEA de processo e que esse método inicia com a análise de falhas potenciais, as quais têm relação com a confiabilidade do produto e, esse fator, com a questão da qualidade, os três conceitos são revistos segundo vários autores da área, os quais são apresentados na Tabela 1.

Revista Produção Online. Florianópolis, SC, v.11, n. 4, p. 995-1027, out./dez. 2011. 
Tabela 1 - Conceitos relacionados à qualidade, confiabilidade e falha

\begin{tabular}{|c|c|}
\hline Autor (Ano) & onados à qualidade, confiabilidade e falha \\
\hline Xenos (1998) & $\begin{array}{l}\text { Qualidade é a forma pela qual os produtos e serviços são julgados pelos } \\
\text { usuários. O foco do processo de garantia da qualidade é o de assegurar a } \\
\text { conformidade do produto com o que foi especificado. Essa conformidade é } \\
\text { medida pela variação das características do produto em torno dos valores } \\
\text { especificados. }\end{array}$ \\
\hline $\begin{array}{l}\text { Jiang e } \\
(2009)\end{array}$ & $\begin{array}{l}\text { A qualidade do produto apresenta várias dimensões e a confiabilidade é } \\
\text { uma delas, a qual trata do desempenho do produto durante certo tempo. } \\
\text { Entre as caracterizações da confiabilidade tem-se a binária; itens conforme } \\
\text { ou não conforme. A confiabilidade de itens não conformes é muito menor do } \\
\text { que a dos itens conformes. }\end{array}$ \\
\hline Martins (2001) & $\begin{array}{l}\text { A qualidade de um produto deve contemplar oito elementos: } \\
\text { características operacionais principais; características operacionais } \\
\text { adicionais; conformidade às normas e às especificações técnicas; } \\
\text { apresentar durabilidade; prover assistência técnica para o produto, porém, } \\
\text { minimizar a sua necessidade; dar atenção à estética do produto; contar com } \\
\text { a qualidade percebida pelo usuário e apresentar produtos de alta } \\
\text { confiabilidade. }\end{array}$ \\
\hline Lafraia (2001), & $\begin{array}{l}\text { Produto confiável é aquele que apresenta poucas falhas à medida que } \\
\text { envelhece, pois as falhas dos equipamentos são mais comuns na sua } \\
\text { implantação e no final da sua vida útil. Segundo o autor, a taxa de defeitos } \\
\text { de um componente é dada por falhas por unidade de tempo e varia com o } \\
\text { tempo de vida de cada componente. }\end{array}$ \\
\hline Slack & $\begin{array}{l}\text { dade é a habilidade de um sistema, produto ou serviço } \\
\text { har-se como o esperado durante certo intervalo de tempo. }\end{array}$ \\
\hline $\begin{array}{l}\text { Abacke } \\
(2007)\end{array}$ & $\begin{array}{l}\text { Confiabilidade caracteriza as chances do produto ainda estar em } \\
\text { funcionamento ao término de uma missão realizada em um intervalo de } \\
\text { tempo definido. }\end{array}$ \\
\hline $\begin{array}{l}\text { Kenet } \\
(1998\end{array}$ & $\begin{array}{l}\text { é a probabilidade de um componente ou sistema sobreviver } \\
\text { om duração e condições de uso determinadas. }\end{array}$ \\
\hline $\begin{array}{l}\text { Norma } \\
\text { NBR 5462-1994 }\end{array}$ & $\begin{array}{l}\text { desempenhar } \\
\text { ou substituído. } \\
\text { ja conhecida. }\end{array}$ \\
\hline $\begin{array}{l}\text { Comité } \\
\text { Distrib }\end{array}$ & $\begin{array}{l}\text { ponde a todo evento que produz a perda de capacidade de um } \\
\text { ou sistema desempenhar sua função, levando-os à condição } \\
\text { inadmissível. }\end{array}$ \\
\hline Sinha & jilidade de um componente de executar a função requerida. \\
\hline $\begin{array}{l}\text { Rausand e Oien } \\
\text { (1996) }\end{array}$ & $\begin{array}{l}\text { Falha é um conceito fundamental para a análise da confiabilidade, definida } \\
\text { como o término da habilidade de um item para o desempenho de uma } \\
\text { requerida função. }\end{array}$ \\
\hline & $\begin{array}{l}\text { Falhas são classificadas em modos de falhas, os quais são definidos como } \\
\text { o efeito pelo qual uma falha é observada, ou seja, como se observa o } \\
\text { defeito. }\end{array}$ \\
\hline Nunes & $\begin{array}{l}\text { Modo de falha é a maneira pela qual um determinado item deixa de } \\
\text { executar sua função. }\end{array}$ \\
\hline IEC 50 (1990) & $\begin{array}{l}\text { Falha é o evento onde a função requerida é interrompida, excedendo os } \\
\text { limites aceitáveis. A causa da falha é definida como a circunstância, } \\
\text { durante o projeto, manufatura ou uso, que tenha conduzido à falha. }\end{array}$ \\
\hline
\end{tabular}

Fonte: Elaborado pelos autores

Como pôde ser visto, os conceitos se complementam e, em alguns casos, coincidem em suas definições. De qualquer forma, a confiabilidade adquire importância em função do seu potencial para o aumento de produtividade (nas

Revista Produção Online. Florianópolis, SC, v.11, n. 4, p. 995-1027, out./dez. 2011. 
indústrias) e melhoria da qualidade dos produtos. A estimação adequada do desempenho do produto em campo permite identificar oportunidades de aumento de confiabilidade e qualidade do produto (Lawless,1998 apud Biasoli, 2003). Lafraia (2001) relata que, entre os benefícios da confiabilidade, estão os seguintes: aumentar os lucros através de menores custos de manutenção, fornecer soluções às atuais necessidades das indústrias, aumentar o lucro da produção/unidades e permitir a aplicação de investimentos com base em informações quantitativas (segurança, continuidade operacional e meio ambiente).

Apesar da importância da confiabilidade, sempre há a probabilidade de ocorrerem imprevistos. Entretanto, nem todos são críticos; é preciso identificar os diferentes tipos de falhas e prestar atenção nas que são críticas por si só ou que possam vir a prejudicar o resto da produção. Para isso, é preciso entender por que algo falha e ser capaz de medir o impacto dessa falha. Uma proposta nesse sentido pode ser vista em Aguiar e Salomon (2007). Afinal, segundo Slack et al. (2002), as falhas na produção podem ser agrupadas em falhas de projeto, de instalação, de pessoal, de fornecedores e de clientes, as quais podem ter impactos diferenciados na produção.

Moubray (1991) cita que a origem de todas as falhas tem relação com o erro humano. A falha de uma máquina pode ter sido causada por um projeto ruim, uma manutenção precária, uma falha na entrega, erros de gestão, erro por parte do cliente ou por falha nas instruções. Entretanto, as falhas raramente são resultados de aleatoriedades; elas normalmente advêm do homem. Nesse sentido, Juran (1997) classifica os erros humanos em três categorias: erros por falta de conhecimento ou habilidade; erros por ignorância das regras ou normas e erros por falta de atenção.

É importante ressaltar que as falhas podem ser controladas até certo ponto e pode-se aprender com elas. A conscientização disso levou ao conceito de "falha como oportunidade". Elas são vistas como uma oportunidade para examinar o porquê da sua ocorrência, visando programar procedimentos que eliminem ou reduzam a probabilidade delas ocorrerem novamente.

Moore (1997) cita sete mecanismos para procurar falhas: as verificações no processo; a investigação de acidentes; o diagnóstico de máquinas; a análise de 
reclamações; entrevistas e questionários; grupos de foco e métodos para a análise de falhas. Entre os métodos que se propõe a auxiliar na análise de falhas, visando à sua prevenção, detecção e controle estão: a Análise de Modos e Efeitos de Falhas (FMEA, Failure Mode and Effect Analysis), a Análise de Perigos e Operabilidade (HAZOP, Hazard and Operability Analysis) e a Análise da Árvore de Falhas (FTA, Failure Tree Analysis). Destes, o FMEA tem sido o mais utilizado na análise da confiabilidade de projetos (Palady, 1997). O objetivo desse método é detectar uma falha antes que se produza a peça ou produto. Com a sua utilização, diminui-se a probabilidade da falha ocorrer, buscando, assim, o aumento da confiabilidade desejada.

\subsection{FMEA}

Conforme Puente et al. (2002), o método FMEA é útil para identificar as falhas atuais e potenciais e seus efeitos em sistemas e processos, visando reduzir ou eliminar o risco associado à falha. Ele é um método analítico e padronizado (Stamatis, 2003) e, conforme Palady (1997), é a técnica de baixo risco mais eficiente para prevenir problemas e identificar soluções.

O manual complementar do FMEA da QS 9000 define a técnica como um grupo de atividades sistêmicas com o objetivo de: reconhecer e avaliar a falha potencial de um produto/processo e seus efeitos; identificar ações que possam eliminar ou reduzir a probabilidade do modo de falha potencial vir a ocorrer e documentar o processo de análise.

Historicamente, esse método foi utilizado pela Volkswagen na década de 50 e, posteriormente, foi desenvolvido pela NASA em 1963. Em 1977 passa a ser utilizado de forma abrangente para apoiar a fabricação de automóveis na Ford Motor Company (Fernandes e Rebelato, 2006).

Este método utiliza-se de métricas para avaliar a gravidade da falha do ponto de vista da "ocorrência, severidade e detecção", as quais são multiplicadas entre si, resultando no Número de Prioridade de Risco (NPR), o qual indica se há ou não a necessidade de tomada de ações corretivas. Quanto maior o valor do NPR, mais alto é o risco da falha.

Revista Produção Online. Florianópolis, SC, v.11, n. 4, p. 995-1027, out./dez. 2011. 
Slack et al. (2002) sugerem que para cada causa sejam feitos os seguintes questionamentos: "qual é a probabilidade da falha ocorrer - ocorrência", "qual é a sua conseqüência desta falha - severidade" e "com qual probabilidade esta falha pode ser detectada antes de afetar o cliente - detecção". Esses questionamentos conduzem a um raciocínio de "baixo para cima", procurando determinar os modos de falha e as suas causas e como eles afetam os níveis superiores do sistema (Silva et al., 1997).

Vários estudos foram realizados em torno do tema "FMEA", os quais vêm contribuindo para o amadurecimento do método e de sua estratégia de aplicação. Entre esses, alguns são apresentados na Tabela 2, a qual apresenta a abordagem de vários estudos e seus principais resultados. 
Tabela 2 - Estudos relacionados ao método FMEA e seus resultados

\begin{tabular}{|c|c|c|}
\hline Autor(es) & Abordagem do artigo & Conclusões \\
\hline $\begin{array}{l}\text { Aguiar e } \\
\text { Salomon } \\
(2007)\end{array}$ & $\begin{array}{l}\text { Mostra irregularidades do FMEA de } \\
\text { Processo em empresas automotivas, } \\
\text { identificando sua priorização quanto à } \\
\text { gravidade de sua ocorrência, } \\
\text { utilizando o método AHP (Analytic } \\
\text { Hierarchy Process). }\end{array}$ & $\begin{array}{l}\text { Analisam onze formulários de FMEA de } \\
\text { Processo de ampla gama de produtos } \\
\text { automotivos, identificando irregularidades } \\
\text { no seu desenvolvimento. O artigo } \\
\text { apresenta a hierarquia das } \\
\text { irregularidades analisadas, considerando } \\
\text { a gravidade da sua ocorrência. }\end{array}$ \\
\hline $\begin{array}{l}\text { Xiao et al. } \\
(2011)\end{array}$ & $\begin{array}{l}\text { Discutem que o FMEA considera o } \\
\text { impacto de uma única falha no sistema } \\
\text { e que, portanto, ele se mostra pouco } \\
\text { prático e eficaz para a análise de } \\
\text { falhas em sistemas complexos. Os } \\
\text { autores partem de um trabalho que } \\
\text { analisa falhas múltiplas } \\
\text { simultaneamente em sistemas } \\
\text { complexos e desenvolvem um método } \\
\text { para explicitar as falhas prioritárias no } \\
\text { sistema e como elas repercutem no } \\
\text { conjunto. }\end{array}$ & $\begin{array}{l}\text { Os autores, através de simulações } \\
\text { numéricas, compravam a eficácia do } \\
\text { método para produtos complexos. } \\
\text { Entre outros fatores, eles consideram um } \\
\text { peso em função da relevância da falha, o } \\
\text { qual gera um impacto no RPN. }\end{array}$ \\
\hline $\begin{array}{l}\text { Arabian- } \\
\text { Hoseynabadi } \\
\text { et al. (2010) }\end{array}$ & $\begin{array}{l}\text { Mostra a aplicação do FMEA em uma } \\
\text { turbina de vento, usando um software } \\
\text { para a análise da confiabilidade. } \\
\text { Posteriormente, eles mostram uma } \\
\text { comparação entre os resultados do } \\
\text { FMEA e os dados obtidos em campo, } \\
\text { quanto à confiabilidade da turbina. }\end{array}$ & $\begin{array}{l}\text { O estudo mostrou que utilizar um } \\
\text { software dessa natureza contribui para } \\
\text { prever a taxa de falhas. Os RPNs obtidos } \\
\text { no FMEA foram comparados com as } \\
\text { taxas reais de falhas em campo, } \\
\text { mostrando um percentual representativo } \\
\text { de similaridade. }\end{array}$ \\
\hline $\begin{array}{l}\text { Arabian- } \\
\text { Hoseynabadi } \\
\text { ET AL. } \\
(2010)\end{array}$ & $\begin{array}{l}\text { Dois robôs mecânicos são analisados } \\
\text { usando o FMEA e as falhas crítica são } \\
\text { determinadas. Ações corretivas são } \\
\text { propostas para ambos, visando } \\
\text { melhorar a confiabilidade e reduzir } \\
\text { riscos de falhas. Posteriormente, } \\
\text { aplicam também o método QFD, } \\
\text { visando melhorar o projeto de acordo } \\
\text { com as necessidades dos clientes. }\end{array}$ & $\begin{array}{l}\text { Com a aplicação do FMEA foi possível } \\
\text { detectar as falhas potenciais nos robôs, } \\
\text { desdobrando em ações preventivas, } \\
\text { visando torná-los mais confiáveis. Com a } \\
\text { aplicação do QFD foi possível obter a lista } \\
\text { dos principais requisitos técnicos de } \\
\text { projeto para os clientes, a qual pode } \\
\text { servir para direcionar as alterações } \\
\text { necessárias nos projetos dos robôs para } \\
\text { que estes atendam melhor os clientes. }\end{array}$ \\
\hline $\begin{array}{l}\text { Rhee e Ishii } \\
(2003)\end{array}$ & $\begin{array}{l}\text { Visando reduzir a subjetividade dos } \\
\text { índices presentes na planilha do } \\
\text { FMEA, esse artigo propõe uma nova } \\
\text { abordagem para o FMEA, baseada } \\
\text { nos riscos em termos de custo durante } \\
\text { o ciclo de vida do produto. }\end{array}$ & $\begin{array}{l}\text { Um estudo com um acelerador de } \\
\text { partículas mostra vantagens na previsão } \\
\text { de custos de falhas durante o ciclo de } \\
\text { vida do produto, quantificando riscos e } \\
\text { auxiliando no planejamento e } \\
\text { programação de manutenções, } \\
\text { melhorando, o desempenho da máquina. }\end{array}$ \\
\hline $\begin{array}{l}\text { Almeida et } \\
\text { al. (2006) }\end{array}$ & $\begin{array}{l}\text { Sugerem um mapeamento de falhas } \\
\text { para analisá-las no FMEA. O } \\
\text { mapeamento mostra o processo de } \\
\text { formação de falhas e pode ser } \\
\text { elaborado com o auxílio de várias } \\
\text { ferramentas. }\end{array}$ & $\begin{array}{l}\text { Os autores investigam e recomendam } \\
\text { três ferramentas para mapear falhas: } \\
\text { Fault Tree Analysis (FTA), Event Tree } \\
\text { Analysis (ETA) e o Diagrama de Árvore } \\
\text { ou Diagrama Sistemático. }\end{array}$ \\
\hline
\end{tabular}

Fonte: Elaborada pelos autores

Considerando o objetivo desse trabalho, que é o de explorar as estratégias adotadas pelos fornecedores das automotivas para preencher o FMEA de processo

Revista Produção Online. Florianópolis, SC, v.11, n. 4, p. 995-1027, out./dez. 2011. 
e verificar a confiabilidade do seu preenchimento, um estudo realizado em campo industrial é apresentado.

\subsubsection{Análise do preenchimento do FMEA em campo}

Dos fornecedores investigados, dois são de grande porte, dois de médio e três de pequeno porte. Os sete estão geograficamente distribuídos nos estados de São Paulo, Minas Gerais e Paraná.

Visando compreender a estratégia de desenvolvimento do FMEA, primeiramente questionou-se sobre o número de pessoas que participam das reuniões. O Quadro 1 mostra que apenas três desenvolvem as reuniões de FMEA com quatro ou mais pessoas.

Quadro 1 - Número de participantes na reunião de FMEA.

\begin{tabular}{|l|c|c|c|c|c|c|c|}
\hline EMPRESA & $\begin{array}{c}\mathrm{A}(\mathrm{MG}) \\
\text { Grande } \\
\text { porte }\end{array}$ & $\begin{array}{c}\mathrm{B}(\mathrm{SP}) \\
\mathrm{Grande} \\
\text { porte }\end{array}$ & $\begin{array}{c}\mathrm{C}(\mathrm{SP}) \\
\text { Médio } \\
\text { porte }\end{array}$ & $\begin{array}{c}\mathrm{D}(\mathrm{SP}) \\
\text { Médio } \\
\text { porte }\end{array}$ & $\begin{array}{c}\mathrm{E}(\mathrm{PR}) \\
\text { Pequeno } \\
\text { porte }\end{array}$ & $\begin{array}{c}\mathrm{F}(\mathrm{PR}) \\
\text { Pequeno } \\
\text { porte }\end{array}$ & $\begin{array}{c}\mathrm{G}(\mathrm{PR}) \\
\text { Pequeno } \\
\text { porte }\end{array}$ \\
\hline $\begin{array}{l}\text { De 2 a 3 } \\
\text { pessoas }\end{array}$ & & $\mathrm{X}$ & $\mathrm{X}$ & $\mathrm{X}$ & $\mathrm{X}$ & $\mathrm{X}$ \\
\hline $\begin{array}{l}\text { De 4 a 5 } \\
\text { pessoas }\end{array}$ & $\mathrm{X}$ & & & & & & \\
\hline Mais de 5 \\
pessoas
\end{tabular}

Em seguida foi verificado o número de pessoas por departamento que participam na elaboração do FMEA, visando compreender o nível de integração existente, os quais estão representados no Quadro 2. 
Quadro 2 - Número de pessoas por departamento que desenvolvem o FMEA.

\begin{tabular}{lccccccc}
\hline EMPRESA & $\begin{array}{c}\mathrm{A}(\mathrm{MG}) \\
\text { Grande porte }\end{array}$ & $\begin{array}{c}\mathrm{B}(\mathrm{SP}) \\
\text { Grande } \\
\text { porte }\end{array}$ & $\begin{array}{c}\mathrm{C}(\mathrm{SP}) \\
\text { Médio } \\
\text { porte }\end{array}$ & $\begin{array}{c}\mathrm{D}(\mathrm{SP}) \\
\text { Médio } \\
\text { porte }\end{array}$ & $\begin{array}{c}\mathrm{E}(\mathrm{PR}) \\
\text { Pequeno } \\
\text { porte }\end{array}$ & $\begin{array}{c}\mathrm{F}(\mathrm{PR}) \\
\text { Pequeno } \\
\text { porte }\end{array}$ & $\begin{array}{c}\mathrm{G}(\mathrm{PR}) \\
\text { Pequeno } \\
\text { porte }\end{array}$ \\
\hline Qualidade & 1 & 1 & 1 & 1 & 1 & 1 & 1 \\
Engenharia & 2 & 1 & 2 & 1 & 1 & 1 & 1 \\
Manufatura & 1 & 2 & 1 & 1 & 1 & 1 & 1 \\
$\begin{array}{l}\text { Ferramentaria } \\
\text { Logística }\end{array}$ & 1 & 1 & 1 & 1 & & & \\
$\begin{array}{l}\text { Cliente } \\
\text { (montadora) }\end{array}$ & 1 & & & & & & \\
Outros & & & & & & & \\
\hline
\end{tabular}

Observa-se que quanto maior o porte da empresa, maior é o número de departamentos participantes, devido à subdivisão das especialidades. Destaca-se, também, a participação dos operadores na "empresa A" e a falta de participação da montadora em todas as empresas.

A seguir, questionou-se sobre o tempo gasto para a elaboração do FMEA e se esse tempo era considerado elevado. Apesar de três fornecedores terem reuniões de no máximo duas horas e apenas um consumir mais de quatro horas, todos consideravam a reunião de FMEA muito demorada.

Como o FMEA não é um método simples de se utilizar, foi questionado se para participar da reunião era exigido algum conhecimento sobre o FMEA de Processo. Nas empresas de grande porte, todos tinham o domínio do método, porém, nas de médio e pequeno porte esta condição não era exigida e, portanto, nem sempre os presentes tinham conhecimento sobre o método.

Após essa investigação inicial, buscou-se coletar dados específicos das planilhas de FMEA, visando identificar o nível das irregularidades existentes no seu preenchimento. Com a coleta de dez FMEA's de Processo de cada fornecedor, preenchidas em 2008 e 2009, relacionadas a um processo de estampagem de metal a frio, as planilhas foram analisadas e comparadas.

\subsubsection{Comparação dos dados preenchidos na planilha do FMEA}

A investigação foi baseada na folha de análise padrão, recomendada pelo Instituto de Qualidade Automotiva. Cada coluna da planilha foi denominada por uma Revista Produção Online. Florianópolis, SC, v.11, n. 4, p. 995-1027, out./dez. 2011. 
letra e todas elas foram comparadas separadamente, considerando a amostra coletada (Ver Figura 1).

Figura 1 - Folha de Análise do FMEA de Processo coletada.

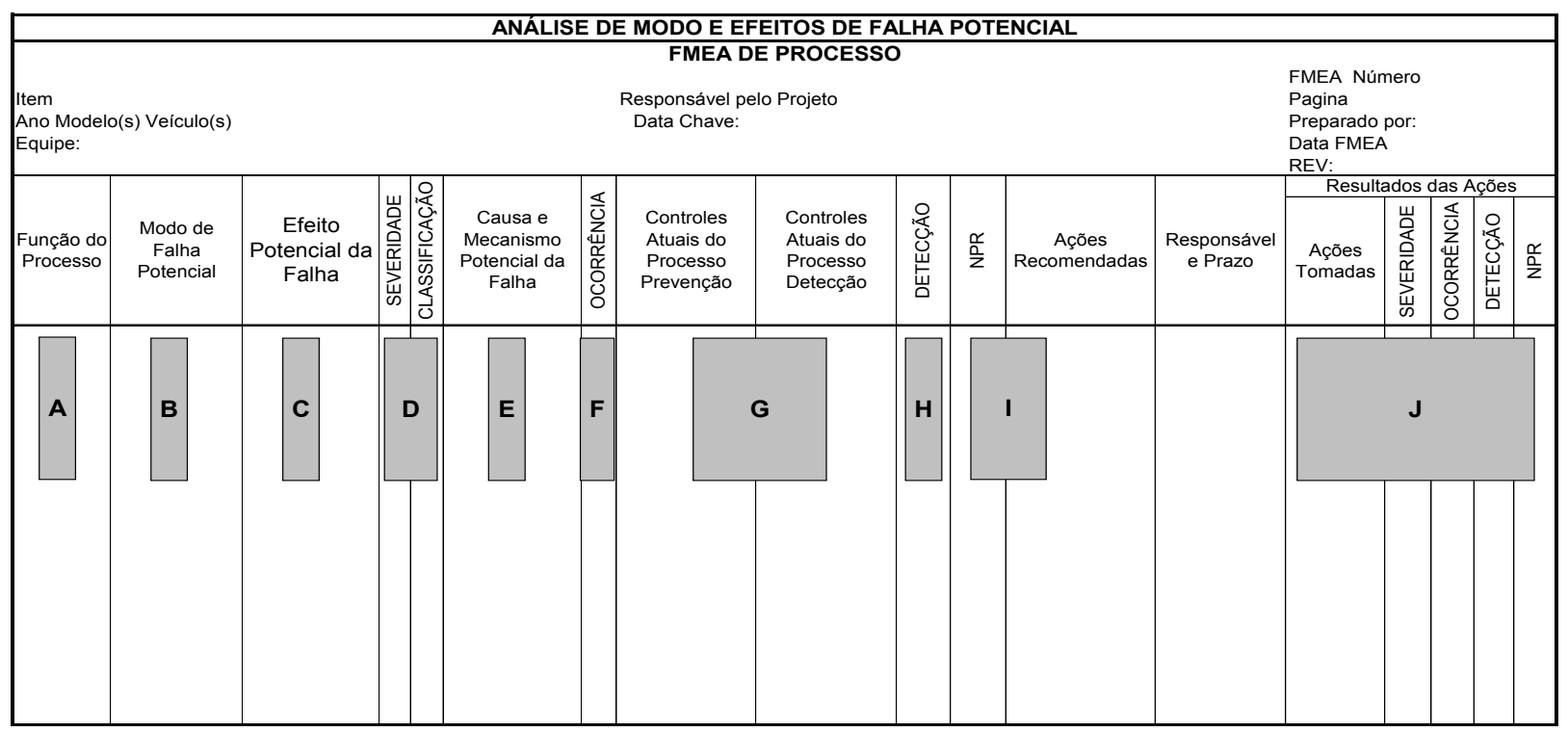

O resultado das comparações dos FMEA's coletados está descrito por coluna, ressaltando as que apresentam discrepância e as que apresentam coerência entre os valores coletados junto aos fornecedores.

\section{Coluna A - Função do Processo}

Com o objetivo de padronizar as informações referentes ao processo de estampagem, as principais operações ou funções preenchidas nas folhas de análise de cada um dos sete fornecedores foram tabuladas. Apesar de empresas diferentes, com características diferentes no processo, as operações do processo de conformação mecânica são poucas e muito similares, independente da complexidade da peça. Sendo assim, a investigação teve como foco as seguintes operações:

1. Receber: recepção de matéria-prima a ser processada;

2. Cortar: operação de corte, a qual gera a forma inicial da peça;

Revista Produção Online. Florianópolis, SC, v.11, n. 4, p. 995-1027, out./dez. 2011. 
3. Estampar: operação de embutimento, responsável pela deformação plástica;

4. Dobrar: operação responsável pela dobra do material;

5. Furar: operação de furação, também conhecida como "puncionamento";

6. Recortar: operação de recortes nas peças, tanto externos como internos;

7. Embalar: operação final do processo, cujo resultado é a peça embalada.

As fases 1 e 7 são funções de apoio ao processo, as quais garantem a qualidade e a confiabilidade, tanto na entrada do fluxo do processo, quanto na saída.

As operações de 2 a 6 são exclusivas do processo de estampagem.

Com a análise dos FMEAs identificou-se que cada fornecedor tem uma maneira própria de nomear as operações do processo de estampagem, o que poderia gerar dificuldades para a análise, já que não existe uniformidade na linguagem adotada.

\section{Coluna B - Modo de Falha Potencial}

Para cada operação citada anteriormente, foi tabulado o número de modos de falhas potenciais descritos pelos fornecedores.

Constatou-se que os fornecedores A, B e C, D (Grande e Médio porte) apresentaram um número similar em relação aos modos de falhas em seus processos de fabricação, enquanto os fornecedores $E, F$ e $G$ (Pequeno porte) apresentaram um número menor. Enquanto os primeiros chegaram a identificar três modos de falha para a operação dobrar, os de pequeno porte apresentaram apenas um modo de falha.

Ressalta-se que, em função da identificação das falhas se desenvolve todo o processo de análise do FMEA e que, portanto, este tópico apresenta grande impacto na planilha, podendo comprometer os resultados finais do FMEA, como cita Aguiar e Salomon (2007). 


\section{Coluna C - Efeito Potencial da Falha}

O efeito da falha refere-se à conseqüência que esta acarreta ao produto e, conseqüentemente, ao usuário. Para cada Modo de Falha pode existir um ou mais efeitos relacionados. Nesse item não se detectou variações significativas entre os fornecedores.

\section{Coluna D - Severidade e Classificação}

Nesta etapa é definido o impacto que o modo potencial de falha tem sobre a operação do sistema e, conseqüentemente, sobre a satisfação do cliente.

Comparando a análise de severidade de cada fornecedor por operação/função do processo, percebe-se uma dispersão nos índices para os mesmos padrões de operações.

Apesar de grande parte dos fornecedores utilizar o padrão recomendado pelo IQA (Instituto de Qualidade Automotiva), os índices de severidade apresentam divergências. Cada fornecedor classifica a severidade utilizando um critério diferente.

Quanto ao tópico "classificação”, apenas três preencheram esta coluna. Ela deveria ser utilizada para classificar qualquer característica especial de produto ou processo para um componente ou sistema que pudesse requerer algum controle adicional.

\section{Coluna E - Causa e Mecanismo Potencial da Falha}

A causa potencial da falha é definida como a forma pela qual a falha pode ocorrer, descrita em termos de algo que possa ser corrigido ou controlado.

Com as análises constatou-se que o número de causas variou muito entre os fornecedores. Em determinada operação, para um efeito, alguns fornecedores apresentaram uma causa, enquanto outros identificaram três.

Segundo o IQA (2002), devem-se listar, da forma mais completa possível, todas as causas de falhas assinaláveis para cada modo de falha potencial. Antes do 
preenchimento desta coluna, métodos como "Projeto de Experimentos" e "Diagrama de Causa e Efeito (também conhecido como Ishikawa ou Espinha de Peixe)" podem ser utilizados para aumentar a confiabilidade do trabalho.

\section{Coluna F - Ocorrência}

O estabelecimento do índice de ocorrência se refere à probabilidade da falha vir a acontecer. Esta pode ser baseada no histórico de falhas, o qual pode ser identificado em processos anteriores, similares ao analisado no momento. Sendo assim, não seria recomendável a comparação deste resultado entre os diferentes fornecedores, pois cada um tem o seu próprio histórico, tornando os resultados diferentes. Porém, é importante salientar que o Instituto de Qualidade Automotiva alerta sobre a subjetividade da avaliação. Afinal, ela poderia comprometer a veracidade das informações, tornando os itens suscetíveis às transformações conforme a conveniência, visando evitar a necessidade de planos de ações. Esse tipo de subterfúgio foi identificado no estudo de Aguiar e Salomon (2007), através da constatação de "variações de pontuação de ocorrência para a mesma causa" entre vários desenvolvedores.

\section{Coluna G - Controles Atuais do Processo (Prevenção e Detecção)}

Nessas colunas são descritos os controles que podem detectar ou prevenir a ocorrência do modo de falha ou o mecanismo da falha. Nesse tópico, todas as análises apresentaram controles detalhados, tanto para a prevenção como para a detecção.

\section{Coluna H - Detecção}

O índice de detecção é a classificação associada com o melhor controle de detecção listado na coluna de controle de processo. Neste tópico também não se considera apropriado comparar as pontuações de cada fornecedor, afinal, se estima que exista certa influência do projeto do processo de fabricação da peça. Sendo 
assim, dependendo da ordem de como as operações de estampagem são projetadas, podem ocorrer variações no índice de detecção.

Detalhando a operação "Recebimento de matéria-prima", constataram-se discrepâncias altas na análise do FMEA de um dos fornecedores. Supõe-se que deva ter sido um erro de análise, pois quanto menor é o índice de detecção, maior é a probabilidade de detecção da falha e vice-versa. Entretanto, este fornecedor usou um alto índice para indicar facilidade de detecção da falha.

\section{Coluna I - Número de Prioridade de Riscos (NPR) e Ações Recomendadas}

O NPR é o produto dos Índices de Severidade, Ocorrência e Detecção. Seu objetivo é indicar as falhas que geram maior risco ao usuário e que, portanto, demandam ações prioritárias. Entretanto, para se verificar a necessidade de ações corretivas devem ser analisados conjuntamente os índices de Severidade, Ocorrência e Detecção. A simples análise ou comparação do NPR não é suficiente para esta decisão.

Palady (1997) sugere que NPR acima de 100 ou índices de severidade maiores que 8 devam conter ações imediatas e/ou preventivas. A mesma exigência é feita pela montadora estudada.

Neste item, todos os fornecedores preencheram as informações, porém, observaram-se discrepâncias com relação à tomada de ações. Houve casos de fornecedores que tomaram ações com NPR equivalente a 40, enquanto outros manifestaram um plano de ação com um índice de severidade igual a sete. Ou seja, para alguns fornecedores não é claro os índices considerados pela montadora para a exigência de tomada de ações.

Na pesquisa de Aguiar e Salomon (2007) o "baixo nível de tomada de ação" foi uma das irregularidades identificadas em campo e uma das de mais alto nível de prioridade dentro do contexto do $F M E A$, já que o método visa gerar ações preventivas. 


\section{Coluna J - Resultados das Ações}

Segundo o IQA (2002), todos os índices revisados deveriam ser analisados criticamente e, se ações adicionais fossem consideradas necessárias, a análise deveria se repetir. O foco deveria ser na melhoria contínua, o que não se constata na prática das empresas estudadas.

De uma forma geral, os FMEA's enviados pelos fornecedores estavam desatualizados, desconsiderando problemas e falhas observados durante a execução do projeto. Ou seja, constatou-se que o FMEA se tornou um documento utilizado para cumprir uma exigência da montadora e não uma fonte de "lições aprendidas com o histórico de falhas", visando uma melhoria contínua do processo de fabricação.

\section{ANÁLISE DOS DADOS COLETADOS}

Considerando as informações levantadas na literatura e os dados coletados através dos questionários e das planilhas de FMEA, os fatores que tendem a influenciar na aplicação do FMEA foram identificados e analisados, cujos resultados estão detalhados na Tabela 3.

Visando organizar a análise, definiram-se sete fatores relevantes nesse tipo de análise, denominados por fatores de influência, os quais foram identificados através da literatura sobre o tema e da coleta realizada juntos aos fornecedores estudados. Os sete fatores são os seguintes: conhecimento, histórico de falhas, trabalho em equipe, sintonia entre fornecedor e montadora, tempo de preenchimento da planilha, treinamento no método e controle no preenchimento dos FMEA's, visando o aproveitamento destas planilhas para a análise de novos processos de fabricação. 
Quadro 3 - Análise dos resultados considerando os fatores de influência (continua)

\begin{tabular}{|l|l|}
\hline & $\begin{array}{l}\text { Constatou-se que as empresas de médio e grande porte apresentam resultados próximos } \\
\text { na identificação dos Modos de Falhas. Isto se deve ao know-how que essas empresas }\end{array}$ \\
apresentam devido aos anos de experiência no ramo automotivo. Além disso, são \\
empresas que investem com freqüência na formação e reciclagem de seus funcionários. \\
As empresas de pequeno porte, por não estarem constantemente sendo cobradas deste \\
tipo de análise, não conseguem fazer ou fazem de maneira inapropriada esse tipo de \\
análise, iniciando o procedimento de forma vulnerável, desconsiderando algumas \\
possibilidades de falhas. Os funcionários também não recebem formação adequada para \\
desenvolver o método em questão.
\end{tabular}

Fonte: Elaborada pelos autores

Quadro 3 - Análise dos resultados considerando os fatores de influência (conclusão)

\begin{tabular}{|l|l|}
\hline & $\begin{array}{l}\text { O fornecedor preenche o FMEA, levando em consideração apenas o seu processo de } \\
\text { fabricação. O tópico "classificação" raramente é preenchido, pois o fornecedor muitas } \\
\text { vezes desconhece em que local a peça será montada no veículo, qual a sua função e }\end{array}$ \\
importância. Sendo assim, identifica-se a importância da participação dos membos da \\
montadora na elaboração do FMEA, pois desta forma seria possível identificar possíveis \\
falhas também na linha de montagem da montadora e com o produto em uso. Com esse \\
procedimento, algumas disparidades nos índices de severidades poderiam ser evitadas. \\
De todos os FMEA's analisados, nenhum deles teve a participação da montadora. Ela \\
somente aparece para validar o FMEA, cuja tarefa é realizada exclusivamente pelo grupo \\
de engenharia.
\end{tabular}

Fonte: Elaborada pelos autores.

Revista Produção Online. Florianópolis, SC, v.11, n. 4, p. 995-1027, out./dez. 2011. 


\subsection{Sugestões de melhorias}

Nessa etapa são apresentadas propostas para a minimização dos fatores de influência no FMEA de Processo de produtos estampados, visando à redução da subjetividade nas pontuações, a qual acaba comprometendo a confiabilidade da análise.

Como identificado anteriormente, os itens que apresentam maior divergência são: Modos de Falhas; Severidade; Classificação; Causa Potencial da Falha; Ações recomendadas e Resultados das ações. Analisando esses itens, constata-se que se os Modos de Falhas não são bem diagnosticados, toda a seqüência da análise fica comprometida, sendo esse item, portanto, considerado o mais crítico no preenchimento do FMEA. Isso ficou claro em função da análise dos 70 (setenta) FMEA's recebidos, quando se constatou que havia falta de informação sobre as falhas e suas particularidades, como: modo, severidade, classificação e causa. Sendo assim, sugere-se uma parametrização parcial da planilha para que as análises possuam dados mais uniformes. Para isso, faz-se necessária a criação de uma linguagem comum entre todos os fornecedores, através da padronização dos principais campos a serem preenchidos.

Sendo assim, ficou definido que os itens: função, modo, efeito, severidade, classificação e causas seriam previamente preenchidos pela montadora. Um exemplo de parametrização sugerida pelos autores, considerando as operações envolvidas em um processo de estampagem a frio, está exemplificado na Figura 2, através da função "furar":

Figura 2 - Exemplo de parametrização para a função "furar".

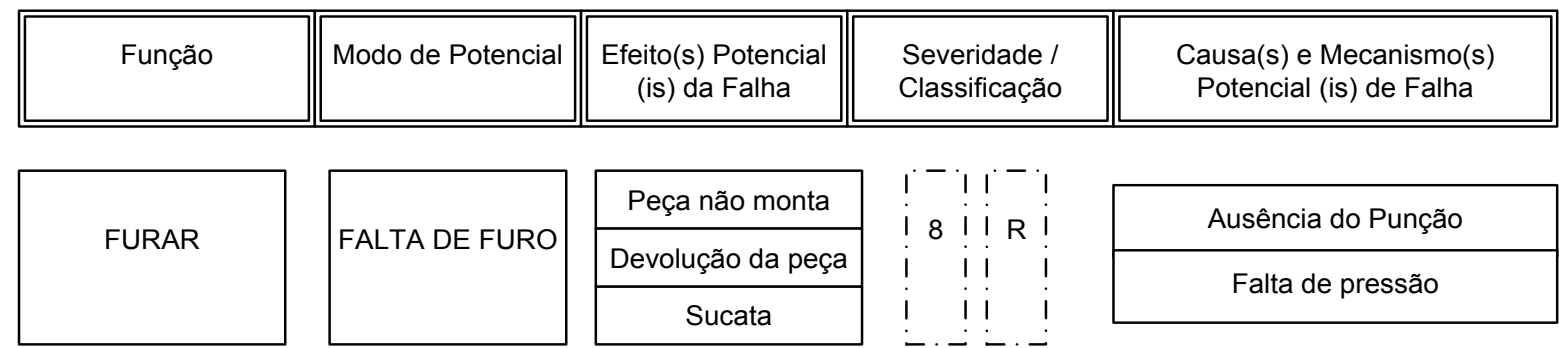

Revista Produção Online. Florianópolis, SC, v.11, n. 4, p. 995-1027, out./dez. 2011. 
As colunas severidade e classificação são bloqueadas, impedindo qualquer manipulação para se obter um resultado impróprio, já que para a severidade observaram-se altos níveis de divergências e para a classificação praticamente não houve indicações.

Quanto às questões relacionadas ao histórico de falhas, a grande dificuldade é sensibilizar os fornecedores quanto à criação e utilização de um banco de dados. Sendo assim, propõe-se utilizar as informações conhecidas através dos FMEA's dos fornecedores e da montadora, visando elaborar uma planilha que agregue esse conhecimento. Dessa maneira, a cada novo projeto ou problema, essa planilha seria enviada aos fornecedores, sendo novamente re-alimentada no sistema de forma contínua. Ou seja, propõe-se que o próprio "FMEA melhorado" contenha o histórico de falhas.

Cria-se, assim, um mecanismo de atualização contínua, o qual fica sob a responsabilidade da montadora, que é a parte mais interessada em obter resultados coerentes.

Os fornecedores, por sua vez, contribuem com as análises, sendo beneficiados por terem uma planilha rica em detalhes e com informações que os ajudarão nas análises de novos desenvolvimentos, acelerando esse procedimento.

Com o objetivo de controlar a evolução do FMEA e contribuir com a atualização do histórico de falhas, sugere-se que, juntamente com a peça, seja enviada para a montadora a planilha do FMEA. Dessa forma, facilita o trabalho do responsável em realizar a gestão dos problemas relacionados às peças dos fornecedores, além de possibilitar a atualização do histórico de falhas por parte da montadora. Atualmente, a empresa recebe o documento do FMEA, porém, após as modificações, a montadora não tem acesso para atualizar a planilha.

Para garantir que o FMEA seja desenvolvido em equipe, recomenda-se que alguém da montadora participe da reunião, criando um compromisso formal, apesar de o fornecedor ser o responsável pela convocação e a organização da reunião. Além da participação na geração dos resultados, a montadora comprova se realmente o trabalho em equipe está sendo realizado. Afinal, a montadora tem informações importantes, provenientes dos clientes finais, que o fornecedor pode desconhecer.

Revista Produção Online. Florianópolis, SC, v.11, n. 4, p. 995-1027, out./dez. 2011. 
A sugestão de participantes, por parte dos fornecedores e montadora, está na Tabela 4, a qual foi baseada também no IQA (2002).

Quadro 4- Sugestão de participantes, por parte dos fornecedores e montadora.

\begin{tabular}{|c|c|}
\hline \multicolumn{2}{|c|}{ Relação de pessoas para a reunião FMEA } \\
\hline FORNECEDOR & CLIENTE (MONTADORA) \\
\hline Chefe de Produção & Engenheiro de Produto \\
\hline Engenheiro de Desenvolvimento de Processo $\left(^{*}\right)$ & Responsável pela Estamparia \\
\hline Engenheiro de Desenvolvimento de Produto $\left(^{*}\right)$ & - \\
\hline Engenheiro de Materiais $\left({ }^{*}\right)$ & - \\
\hline $\mathrm{PCP}$ & - \\
\hline Responsável pela Qualidade dos Fornecedores & - \\
\hline Responsável pela Estamparia & - \\
\hline Responsável pela Ferramentaria & - \\
\hline
\end{tabular}

$\left(^{*}\right)$ Nas empresas de pequeno e médio porte, geralmente essas funções são concentradas em uma única pessoa.

Em relação ao tempo de reunião, recomenda-se no máximo 90 minutos, que é o tempo médio de um filme e o período em que uma pessoa permanece concentrada com facilidade. Apesar dessa sugestão, Barbosa (2006) mostra em sua pesquisa que $90 \%$ das pessoas gastam, em média, de quatro a oito horas por semana em reuniões. Porém, não há um tempo ideal para essa prática. Segundo o autor, uma reunião deve seguir três regras: ter objetivo definido, priorizar tarefas, delegar e cobrar.

No caso do FMEA, contatou-se que o fator mais importante para reduzir o tempo das reuniões era o fato das informações relativas à função, modo, efeito, severidade e causa de falhas estarem previamente definidas pela montadora, baseando-se em históricos anteriores. Além disso, é recomendável que o líder da reunião domine o método FMEA e possua experiência prática no seu desenvolvimento, assim como os demais participantes. A Tabela 5 apresenta uma síntese dos itens de influência no desenvolvimento do FMEA e as sugestões para minimizá-los. 
Quadro 5 - Síntese das melhorias propostas

\begin{tabular}{|c|c|}
\hline $\begin{array}{l}\text { Fatores de } \\
\text { Influência }\end{array}$ & Síntese das Melhorias Propostas \\
\hline $\begin{array}{l}\text { Influência do } \\
\text { conhecimento }\end{array}$ & $\begin{array}{l}\text { a) Padronização das funções do processo } \\
\text { b) Definição prévia pela montadora das funções, modos, efeitos, } \\
\text { severidade, classificação e causas de falhas } \\
\text { c) Planilha idêntica para todos os fornecedores } \\
\text { d) Restrição de acesso às colunas "severidade e classificação" }\end{array}$ \\
\hline $\begin{array}{l}\text { Histórico de } \\
\text { Falhas }\end{array}$ & $\begin{array}{l}\text { a) Utilização do FMEA como um banco de dados de falhas } \\
\text { b) Re-alimentação das informações a cada novo projeto ou problema } \\
\text { identificado }\end{array}$ \\
\hline $\begin{array}{l}\text { Trabalho em } \\
\text { Equipe e Sintonia } \\
\text { entre fornecedor e } \\
\text { montadora }\end{array}$ & $\begin{array}{l}\text { a) Participação do cliente (montadora) na elaboração do FMEA } \\
\text { b) Reunião realizada na empresa do fornecedor } \\
\text { c) Organização e condução da reunião por parte do fornecedor } \\
\text { d) Trabalho desenvolvido em equipe previamente estipulada }\end{array}$ \\
\hline $\begin{array}{l}\text { Tempo para } \\
\text { preenchimento do } \\
\text { método }\end{array}$ & $\begin{array}{l}\text { a) Trabalhar com um objetivo de reunião de no máximo } 90 \text { minutos } \\
\text { b) Utilizar banco de dados atualizado pela montadora } \\
\text { c) Desenvolver o FMEA com uma equipe preparada para o método }\end{array}$ \\
\hline Formação & $\begin{array}{l}\text { a) Líder da reunião é um representante do fornecedor com experiência no } \\
\text { método } \\
\text { barticipantes devem ter o treinamento ou pelo menos conhecer o } \\
\text { método }\end{array}$ \\
\hline Controle & $\begin{array}{l}\text { a) Para cada problema identificado no cliente é obrigatório o envio do } \\
\text { FMEA revisado para a atualização do histórico de falhas }\end{array}$ \\
\hline
\end{tabular}

\subsection{Validação da planilha sugerida para o desenvolvimento do FMEA}

Para testar a eficácia da estratégia sugerida para o desenvolvimento do FMEA, incluindo a planilha parcialmente parametrizada, foi realizado um teste em três dos sete fornecedores que participaram dessa pesquisa. Escolheu-se um fornecedor de cada porte ( $P, M$ e $G$ ) para identificar se haveria variações em função do tamanho da empresa, considerando aqueles que estavam em fase de orçar uma determinada peça estampada para a montadora. Essa peça tem como função a sustentação de clips de passagem de cabos dentro do cofre do motor do veículo (Ver Figura 3). Essa peça foi escolhida em função do baixo número de operações de fabricação, pelo fato de sua geometria ser simples e por estar em processo de nacionalização, o que facilitou o envolvimento dos fornecedores que estavam realizando o orçamento da sua fabricação.

Revista Produção Online. Florianópolis, SC, v.11, n. 4, p. 995-1027, out./dez. 2011. 
Figura 3 - Peça escolhida para validar a estratégia sugerida

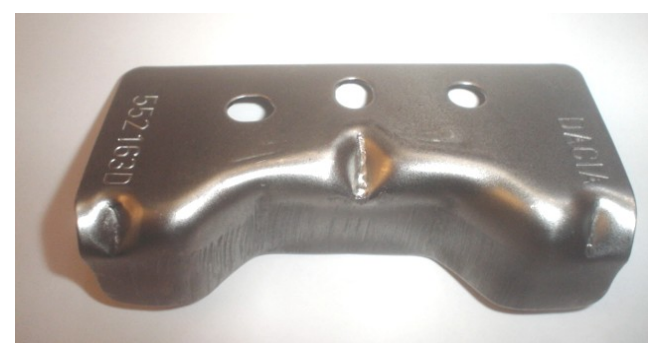

As características detalhadas da peça são as seguintes: Comprimento: 200 mm, Largura: $90 \mathrm{~mm}$, Dobra: 90, Furo : 9mm (1x), Oblongos: 9 x $11 \mathrm{~mm}(2 \mathrm{x})$, Material: XES (X - sem controle de aspecto / ES - estampagem profunda), Peso: 350 gramas e Espessura: 1,17 mm.

Analisando a peça, identificaram-se cinco funções, duas relativas à logística e três ao processo de estampagem. São elas:

- Receber: procedimento de recebimento de uma chapa cortada com dimensões controladas. São verificadas as dimensões, deformações, marcas, camadas de revestimento e especificação química do material;

- $\quad$ Cortar: operação responsável pelo formato inicial e final da peça;

- Furar: operação para realizar o furo de $9 \mathrm{~mm}$ e os 2 oblongos de $9 \times 11$ $\mathrm{mm}$;

- Formar/conformar: realização da dobra e dos vincos que conferem resistência à peça. Apesar de terem funções diferentes, as mesmas são realizadas em uma única operação;

- Embalar: procedimento de armazenamento de peças em embalagens. A quantidade e a posição das peças são definidas conforme a instrução de trabalho para cada posto.

Para o processo logístico "receber", por exemplo, identificaram-se os seguintes modos de falha: matéria-prima incorreta, dimensional abaixo ou acima do especificado, deformação, oxidação ou rebarbas. Para o processo de estampagem foram identificadas as falhas para a operação de corte, cinco para a furação e seis para a conformação.

Uma vez identificados os modos de falhas, foi definido pelo menos um efeito para cada falha. A Figura 4 apresenta parte da parametrização da planilha, mostrando a operação "formar" como exemplo. Em seguida, a Figura 5 apresenta Revista Produção Online. Florianópolis, SC, v.11, n. 4, p. 995-1027, out./dez. 2011. 
uma parte da padronização elaborada para o processo de logística, mostrando o desmembramento da função "receber".

Figura 4 - Desdobramento dos modos de falhas para a função "formar"

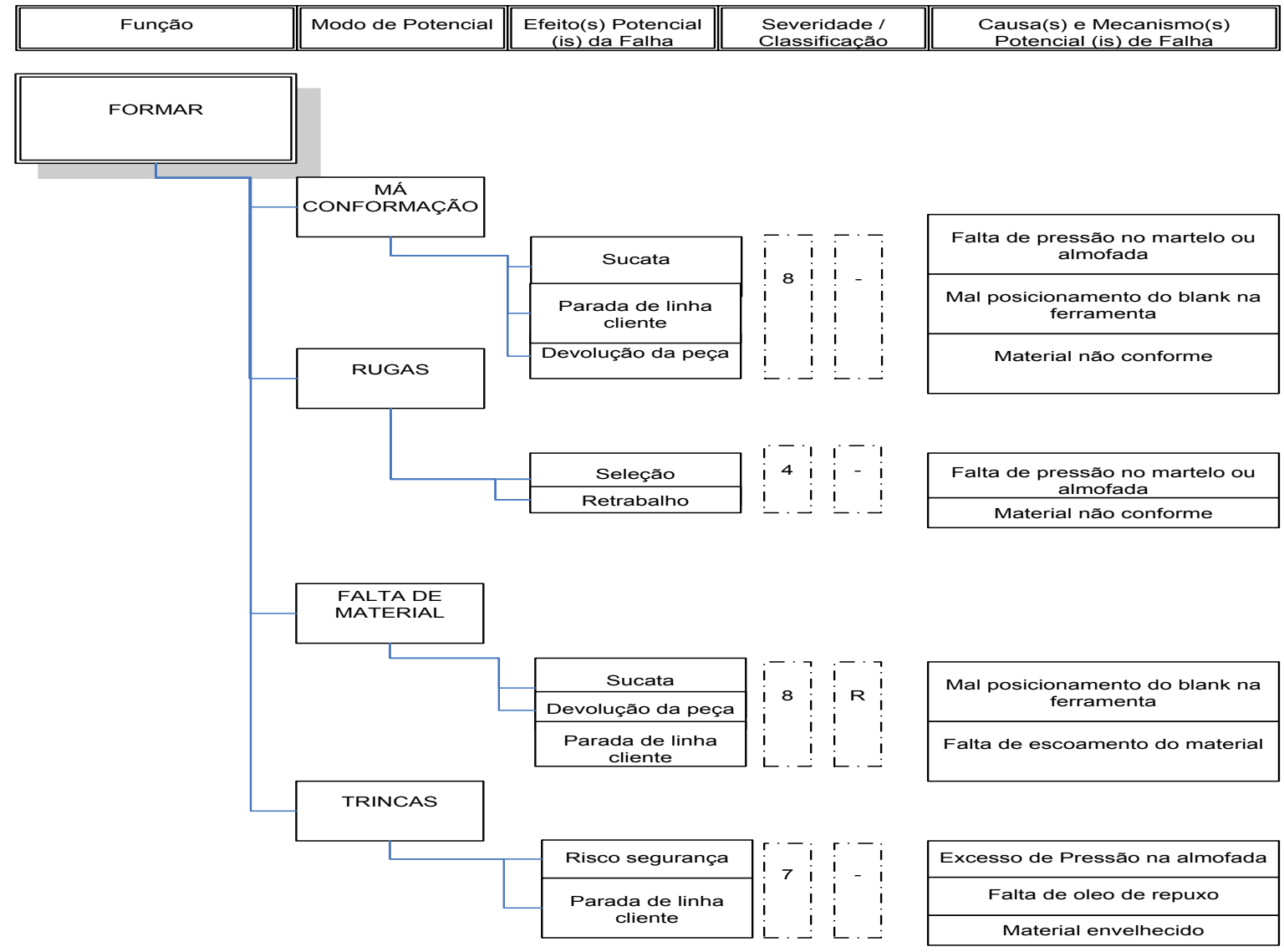

Revista Produção Online. Florianópolis, SC, v.11, n. 4, p. 995-1027, out./dez. 2011. 
Figura 5 - Desdobramento dos modos de falhas para a função "receber"

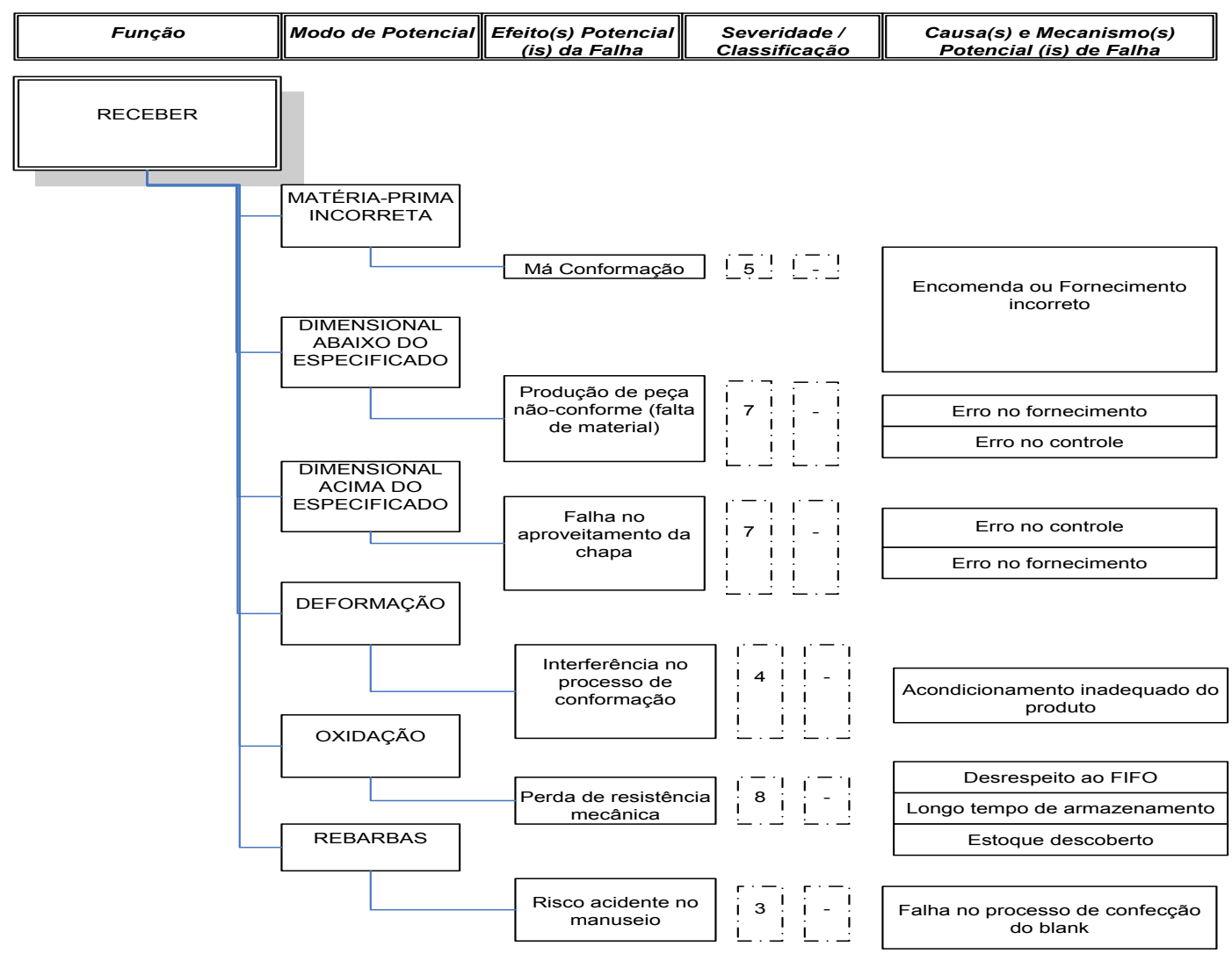

Uma vez formatado os FMEA's, uma reunião foi marcada junto aos três fornecedores e orientações relacionadas à estratégia de desenvolvimento foram repassadas, visando à aplicação das melhorias previamente expostas:

1. O agendamento e a organização da reunião seriam de responsabilidade do fornecedor, sendo o tempo máximo estimado em 90 minutos, a qual deveria envolver a montadora;

2. Os integrantes do grupo para desenvolver o FMEA deveriam ter o domínio do método;

3. As informações referentes aos controles e ocorrências na empresa devem estar disponíveis;

4. Após a reunião, um brainstorming seria realizado, com o intuito de analisar a opinião sobre a nova proposta.

Revista Produção Online. Florianópolis, SC, v.11, n. 4, p. 995-1027, out./dez. 2011. 


\subsection{Análise dos resultados}

Devido à padronização de vários itens e a utilização da mesma planilha nos três fornecedores, não se constatou divergências no seu preenchimento. Para a "Ocorrência" não foi realizada a comparação, pois cada fornecedor possui o seu próprio histórico, conforme a confiabilidade de seus equipamentos.

Devido à existência das informações, relativas às taxas de falhas, o processo de preenchimento ocorreu sem discussões, em menor tempo do que o préestipulado e de maneira confiável.

Com relação aos Controles Atuais do Processo (Prevenção e Detecção), como na primeira fase da investigação, todas as análises apresentaram controles detalhados, tanto para a prevenção, como para a detecção.

Sobre a "Detecção", não foram encontradas as discrepâncias observadas anteriormente, sejam relacionadas aos erros ou ao não entendimento de como funcionava a pontuação deste índice. Conforme recomendações iniciais, os presentes possuíam conhecimento sobre o método.

Para o "Índice NPR" e "Ações Recomendadas", os três fornecedores tomaram ações somente para os NPR's maiores que 50 ou severidade maior do que 7. Essa uniformidade ocorreu em função do novo formulário do FMEA exigir essa padronização. Dessa maneira, eliminou-se a subjetividade que deixava a cargo do fornecedor a escolha da melhor alternativa para a tomada de ações.

Após a realização das reuniões, um Brainstorming foi realizado com o objetivo de identificar os pontos fortes e fracos da nova estratégia e coletar críticas e sugestões dos participantes. Como resultado, obteve-se um total de 43 idéias, sendo 31 relativas aos pontos fortes e fracos e 14 relativas às críticas e sugestões de melhorias. Sintetizando os resultados, tem-se:

- Pontos Fortes: redução do tempo de reunião, agilidade no processo, redução de erros no preenchimento, padronização e participação do cliente;

- Pontos fracos: falta de macros que automatizem o processo de preenchimento, sem campos para inserção de novas falhas e utilização da tabela Excel, sendo esta muito rígida;

- Sugestões: utilizar Microsoft Access e não Excel, criar macros e deixar a planilha aberta para possíveis alterações durante a reunião.

Revista Produção Online. Florianópolis, SC, v.11, n. 4, p. 995-1027, out./dez. 2011. 


\subsection{Melhoria do procedimento com a nova estratégia}

Após as análises, os dois resultados foram comparados, ou seja, os obtidos no primeiro levantamento junto aos sete fornecedores, com a estratégia praticada por eles, e os obtidos junto a três desses fornecedores, os quais testaram a abordagem proposta. A Tabela 6 apresenta um resumo das duas estratégias; a praticada pelos fornecedores e a estratégia sugerida pelos autores.

Quadro 6 - Comparação do desenvolvimento usual do FMEA com a estratégia sugerida

\begin{tabular}{|c|c|c|c|}
\hline & Designação & FMEA Atual & FMEA Melhorado \\
\hline \multirow{12}{*}{ 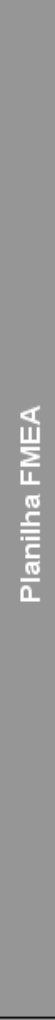 } & Fuıção do Processo & a critério de cada fornecedor & definido pelo cliente conforme histórico de FMEA's \\
\hline & Modo de Falha & a critério de cada fornecedor & definido pelo cliente conforme histórico de FMEA's \\
\hline & Efeito do Modo de Falha & a critério de cada fornecedor & definido pelo cliente conforme histórico de FMEA's \\
\hline & Severidade & $\begin{array}{l}\text { grande parte considerava a severidade em } \\
\text { sua planta e năo no cliente. A tabela de } \\
\text { escolha utilizada nẵo era padronizada }\end{array}$ & $\begin{array}{l}\text { de acordo com o efeito no cliente final. Tabela de } \\
\text { escolha de severidade única para todos os } \\
\text { fornecedores presente no formulário }\end{array}$ \\
\hline & Classificação & muitos casos nẫo considerada & $\begin{array}{l}\text { o cliente define a classificaçấo de acordo com a } \\
\text { criticidade em sua planta }\end{array}$ \\
\hline & Causa e Mecanismo da Falha & a critério de cada fornecedor & definido pelo cliente conforme histórico de FMEA's \\
\hline & Ocorrência & $\begin{array}{c}\text { Altamente subjetivo. A tabela de escolha } \\
\text { utilizada nẫo era padronizada }\end{array}$ & $\begin{array}{c}\text { necessária a apresentação de resultados } \\
\text { estatísticos na reunião devendo estes serem } \\
\text { levantados com antecedência. Lembra-se que } \\
\text { todos os fornecedores estudados possuem ISO } \\
9000 \text { devendo possuir controles em seu } \\
\text { processo. Tabela de escolha de Ocorrência única } \\
\text { para todos os fornecedores (presente no } \\
\text { formulário) }\end{array}$ \\
\hline & Controles (Prevenção/Detecção) & específicos de cada fornecedor & específicos de cada fornecedor \\
\hline & Detecção & $\begin{array}{l}\text { em alguns casos erros no preenchimento } \\
\text { devido a falta de conhecimento. A tabela de } \\
\text { escolha utilizada năo era padronizada }\end{array}$ & $\begin{array}{c}\text { exigido formação ou conhecimento do método para } \\
\text { participar da reuniẫo. Tabela de escolha de } \\
\text { Detecção única para todos os fornecedores } \\
\text { presente no formulário }\end{array}$ \\
\hline & NPR & sem definiçẫo dos valores para definir açỗes & $\begin{array}{c}\text { padronizado que para valores de NPR } 50 \text { ou } \\
\text { severidade }>7 \text { é obrigatório o registro de açôes de } \\
\text { reduçẫo do indice. Inserido na planilha FMEA } \\
\text { estes valores }\end{array}$ \\
\hline & Ações Recomendadas & $\begin{array}{c}\text { presentes de acordo com o entendimento do } \\
\text { fornecedor }\end{array}$ & açổes inseridas conforme o resultado do NPR \\
\hline & Resultados das Ações & sem controle de revisấo & revisẫo conforme problema no cliente \\
\hline \multirow{7}{*}{ 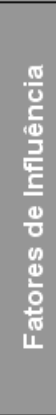 } & Conhecimento & centralizado e dependente das pessoas & universal e da empresa \\
\hline & Histórico de Falhas & nẫo interligado ao FMEA. & $\begin{array}{l}\text { a própria planilha se torna uma fonte histórica de } \\
\text { falhas }\end{array}$ \\
\hline & Trabalho em Equipe & $\begin{array}{c}\text { dúvidas sobre a real participação de todas as } \\
\text { pessoas mencionadas no cabeçalho do } \\
\text { FMEA }\end{array}$ & $\begin{array}{l}\text { cliente participa da reuniấo confirmando a } \\
\text { participaçẫo dos diversos setores do fornecedor }\end{array}$ \\
\hline & Sintonia Fornecedor Montadora & sem participação do cliente na reuniẫo & $\begin{array}{l}\text { participaçấo do cliente na reuniấo sendo esta } \\
\text { realizada no fornecedor }\end{array}$ \\
\hline & Tempo de Preenchimento & demorado (mais de 2 horas) & bom (menos de 2 horas) \\
\hline & Treinamento & $\begin{array}{l}\text { existência de pessoas na reuniấo sem } \\
\text { formaçẫo ou conhecimento do método }\end{array}$ & $\begin{array}{l}\text { exigência de conhecimento do método para } \\
\text { participar da reuniấo }\end{array}$ \\
\hline & Controle & sem controle de revisẫo & $\begin{array}{l}\text { conforme problemas no cliente o FMEA deve ser } \\
\text { atualizado e enviado juntamente com o } 8 \mathrm{D}\end{array}$ \\
\hline
\end{tabular}

Como pôde ser visto, a padronização das funções do processo, os seus modos, efeitos, severidade, classificação e causas de falhas garantiram mais

Revista Produção Online. Florianópolis, SC, v.11, n. 4, p. 995-1027, out./dez. 2011. 
uniformidade nas análises, diminuindo ou, até mesmo, impedindo erros por falta de conhecimento.

Apesar de comentários sobre o excesso de rigidez na planilha sugerida, ressalta-se que a mesma é parte de um teste piloto, sendo desejável que a mesma se ajuste às reais necessidades das empresas com o decorrer do tempo. Além disso, toda a padronização se baseou em dados fornecidos pelos próprios fornecedores e montadora, somados aos conceitos advindos da literatura. $O$ importante é que o conhecimento dessa abordagem passou a figurar no nível da empresa e não mais no do indivíduo.

Tanto nas reuniões, quanto no brainstorming, ficou nítida a redução do tempo gasto para o preenchimento do método, gerando um contentamento geral com relação a esse tópico. Isso ocorreu em função da organização e da padronização de alguns itens, além da solicitação antecipada do histórico de falhas de cada fornecedor.

Para melhorar o trabalho em equipe e o relacionamento fornecedormontadora, a realização da reunião no fornecedor com a participação da montadora foi essencial. O fornecedor passou a dar mais importância ao procedimento, compreendendo que seria necessário discutir a planilha em grupo, com a representatividade de diversos setores da empresa.

O FMEA funcionando como um "histórico de falhas continuamente atualizado" passa a representar uma fonte de "lições aprendidas". Estima-se que, dessa forma, a qualidade das análises tenda a melhorar continuamente, pois um novo projeto sempre contará com uma planilha repleta de informações de outros projetos ou da produção.

A formação e o conhecimento sobre o método mostraram ser fundamentais para uma boa análise, pois pessoas que desconhecem o método podem sair do foco central do grupo, prejudicando a reunião.

Sobre o controle das revisões, torna-se fundamental a revisão do FMEA quando houver problemas de qualidade na montadora. 


\section{CONCLUSÕES}

Através de informações provenientes de sete fornecedores de peças estampadas para uma montadora de automóveis, situada no Estado do Paraná, constataram-se irregularidades no preenchimento do FMEA de Processo.

Com o estudo pôde-se constatar que as empresas de grande porte contam com funcionários mais bem preparados para o desenvolvimento do FMEA, além de contar com grupos maiores nas reuniões e apresentarem mais tempo para o desenvolvimento, o que impacta em FMEA's mais bem elaborados. Sendo assim, as empresas de Grande Porte apresentam FMEA's de melhor qualidade do que as de Pequeno e Médio porte, ainda que todas sejam fornecedoras da mesma peça para uma determinada montadora de automóveis.

Apesar do processo de estampagem possuir operações padronizadas, constatou-se que não se usa uma linguagem uniforme no preenchimento da planilha, o que dificulta a interpretação dos resultados. Além disso, constatou-se uma falta de conhecimento do produto e como a peça analisada irá se encaixar no conjunto, o que tende a comprometer a qualidade do FMEA desenvolvido pelos fornecedores, quando esses não contam com a presença da montadora nas reuniões.

Também foram constatadas discrepâncias na definição dos índices de severidade, ocorrência e detecção, o que explicita a subjetividade do método. Observou-se que parte dessa subjetividade reside na falta de organização das empresas em manter um histórico de falhas atualizado. Esse fato vai contra as diretrizes do Instituto de Qualidade Automotiva, o qual preza pela melhoria contínua.

Considerando o nível de desatualização dos FMEA's analisados, constata-se que não ocorre uma utilização do mesmo como um histórico de análise de falhas potenciais, nem como meio de melhoria do produto ou processo ao longo do tempo.

Considerando esses fatos, foi sugerida uma estratégia de desenvolvimento do FMEA, incluindo uma planilha parcialmente parametrizada, a qual seria mantida atualizada pela própria montadora. Testando essa estratégia em três dos sete fornecedores estudados, considerando a mesma peça estampada, concluiu-se que é

Revista Produção Online. Florianópolis, SC, v.11, n. 4, p. 995-1027, out./dez. 2011. 
possível reduzir os níveis de subjetividade do método, bem como a influência de fatores de divergência em sua aplicação.

Os fatores que mais apresentaram melhoria com a aplicação da nova estratégia foram a "influência do conhecimento" e o "histórico de falhas", quando comparados com a aplicação do FMEA original. Sendo assim, constatou-se a importância de uma boa organização no que se refere à treinamentos, padronização de linguagem relacionada aos processos de fabricação analisados e ao arquivamento e atualização contínua do histórico de falhas.

Além disso, a presença da montadora nas reuniões de desenvolvimento do FMEA mostrou-se vital para garantir um FMEA mais bem elaborado e serviu como uma forma de auditoria para que o desenvolvimento fosse realizado com uma equipe adequada.

Como sugestão para trabalhos futuros, essa estratégia poderia ser melhorada com as opiniões coletadas e testada em um grupo de fornecedores maior, utilizando uma peça com um maior número de operações.

Nota:

Esse trabalho é inédito, resultante de dissertação de mestrado, com dados parciais publicados na Revista Produto e Produção, Vol. 10, N. 2 (2009).

\section{REFERÊNCIAS}

ABACKERLI, A. J.; PAPA' M. C. O.; MIGUEL, P. A. C.; SASSERON, P. L. Análise da incerteza experimental na determinacão da vida usando ensaio acelerado. Gestão e Produção. v. 14, n. 1, p. 69-81, jan./abr. 2007.

AGUIAR, D. C.; SALOMON, V. A. P. Avaliação da prevenção de falhas em processos utilizando métodos de tomada de decisão. Revista Produção, São Paulo, v. 17, n. 3, p.502-519, 2007.

AGUIAR, D. C.; SALOMON, V. A. P. Avaliação da prevenção de falhas em processos utilizando métodos de tomada de decisão. Produção, São Paulo, v. 17, n. 3, dez. 2007.

ALMEIDA, D. A.; LEAL, F.; PINHO, A. F.; FAGUNDES, L. D. Gestão do Conhecimento na análise de falhas: mapeamento de falhas através de sistema de informação. Produção. v. 16, n. 1, jan./abr. 2006.

ALMEIDA, Sérgio. Como cativar o cliente através de um excelente atendimento. $86^{\circ}$ ed. Salvador : Casa da Qualidade, 2003. 143 p.

Revista Produção Online. Florianópolis, SC, v.11, n. 4, p. 995-1027, out./dez. 2011. 
ARABIAN-HOSEYNABADI, H., ORAEE, H., TAVNER, P. J. Failure Modes and Effects Analysis (FMEA) for wind turbines. Electrical Power and Energy Systems, 2010, DOI 10.1016/j.jjepes.2010.01.019.

ASSOCIAÇÃO BRASILEIRA DE NORMAS TÉCNICAS - ABNT. NBR 5462:

confiabilidade e mantenabilidade. Rio de Janeiro: 1994. 37 p.

BARBOSA, C. Reuniões eficazes. Disponível em: < http:// www.triadedotempo.com.br >. Acesso em: 10 abr. 2006.

BIASOLI, P. Modelagem Bayesiana da confiabilidade de produtos a partir de dados de campo de utilização de garantia. 2003. 110 p. Monografia (Trabalho de Conclusão para o Curso de Bacharelado em Estatística) - UFRGS. Porto Alegre, 2003.

CEV. Consultores de engenharia do valor. Disponível em: <http:// www.cev.pt/infotecnica/GestaoValor/proveito_fmea.htm>. Acesso em: 15 mar. 2005.

COMITE DE DISTIBUIÇÂO. Planejamento de sistemas de distribuição. 1. ed., Rio de Janeiro: Campus, 1982. v.1.

FERNANDES, J. M. R.; REBELATO, M. G. Proposta de um método para integração entre QFD e FMEA. Revista Gestão e Produção, São Paulo, v. 13, n. 2, p.245-259, 2006.

FERREIRA, H. S. R.; TOLEDO, J. C. Metodologias e ferramentas de suporte a gestão do processo de desenvolvimento de produto na indústria brasileira de autopeças. In: CONGRESSO BRASILEIRO DE GESTÃO DE DESENVOLVIMENTO DE PRODUTO, 3, 2001. Anais... Florianópolis: UFSC, 2001.

IEC 50 (191). International electrotechnical vocabulary. Chapter 191 -

Dependability and quality of service. Int. Electrotechnical Commission, Geneva, 1990.

IQA: INSTITUTO DE QUALIDADE AUTOMOTIVA. Manuais QS9000: análise do modo e efeitos de falha potencial: FMEA. 2. ed. São Paulo: IQA, 2002, 81 p.

IQA: INSTITUTO DE QUALIDADE AUTOMOTIVA. QS9000: requisitos do sistema de qualidade. 3. ed. São Paulo: IQA, 1998.

JIANG, R.; MURTHY, D.N.P. Impact of quality variations on product reliability. Reliability Engineering and System Safety, v.94, n. 2, p. 490-496, Feb. 2009.

JURAN, J. M., A Qualidade desde o projeto. São Paulo: Livraria Pioneira, 1997. $201 p$.

KENETT, R. S.; ZACKS, S. modern industrial statistic: design and control of quality and reliability. Pacific Grove: Duxbury Press, 1998. 621 p. 
KORAYEM, M. H.; IRAVANI, A. Improvement of 3P and 6R mechanical robots reliability and quality applying FMEA and QFD approaches. Robotics and Computer-Integrated Manufacturing, v. 24, n. 3, p. $472-487,2008$.

LAFRAIA, J. R. B. Manual de confiabilidade, mantenabilidade e disponibilidade. Rio de Janeiro : Qualitymark Petrobrás, 2001. 288p.

MARTINS, P. G. Administração da produção. São Paulo: Saraiva, 2001.

MOORE, R. Combining TPM and reliability-focused maintenance. Plant engineering, v.51, n. 6, 1997.

MOUBRAY, J. Reliability-centred maintenance. Butter-worth-Heinemann, 1991.

NOGUEIRA, M. A.; TOLEDO, J. C. Uma Abordagem para o Uso do FMEA. Banas Qualidade, São Paulo, n.90, p. 62-66, nov. 1999.

NUNES, E. L. Manutenção centrada em confiabilidade (MCC): análise da implantação em uma sistemática de manutenção preventiva consolidada. Dissertação (Mestrado em Eng. Produção) Programa de Pós-Graduação em Engenharia de Produção, Universidade Federal de Santa Catarina, Florianópolis, SC, 2001.

PALADY, Paul. FMEA: análise dos modos de falha e efeitos: prevendo e prevenindo problemas antes que ocorram. São Paulo: IMAM, 1997. 270 p.

PUENTE, J.; PINO, R.; PRIORE, P.; FOUENTE, D de L. A decision support system for applying failure mode and effects analysis. International Journal of Quality \& Reliability Management, Bradford, v. 19, n. 2, 2002.

RAUSAND, M.; IEN, K. The basic concepts of failure analysis. Reliability Engineering and System Safety, n. 53, p. 73-83, 1996.

RHEE, S. J.; ISHII, K. Using cost based FMEA to enhance reliability and serviceability. Advanced Engineering Informatics, v.17, n. 3-4, p. 179-188, Jul./Oct. 2003.

SILVA, C. E. S.; TIN, J. V.; OLIVEIRA, V. C. Uma análise da aplicação da FMEA nas normas de: sistema de gestão pela qualidade (ISO9000 e QS9000), sistema de gestão ambiental (ISO14000) e sistema de gestão da segurança e saúde do trabalho (BS8800 futura ISO18000). In: ENCONTRO NACIONAL DE ENGENHARIA DE PRODUÇÃO, 17, 1997. Anais.... Porto Alegre: UFRGS, 1997.

SINHA, PURNENDU. Architectural design and reliability analysis of a fail-operational brake-by-wire system from ISO 26262 perspectives. Reliability Engineering \& System Safety, 2011, Doi:10.1016/j.ress.2011.06.004. 
SLACK, N.; CHAMBERS, S.; HARLAND, C.; HARRISON, A.; JOHNSTON, R.; Administração da produção. São Paulo: Atlas, 2002. 726 p.

STAMATIS, D. H. Failure mode and effect analysis: FMEA from theory to execution. 2. ed. ASQC, Milwaukee: Quality Press, 2003. 494 p.

TUMER, I. Y., STONE, R. B., BELL, D. G.. Requirements for a failure mode taxonomy for use in conceptual design. In: INTERNATIONAL CONFERENCE ON

ENGINEERING DESIGN - ICED 03, 14th - 2003, Estocolmo - SUE. ICED 03 -

Proceedings. Estocolmo, Suécia: Design Society, Agosto de 2003.

XENOS, H. G. P. Gerenciando a manutenção produtiva. Belo Horizonte: Editora de Desenvolvimento Gerencial, 1998.

XIAO, N.; HUANG, HONG-ZHONG; LI, Y.; HE, LIPING; JIN, T. Multiple failure modes analysis and weighted risk priority number evaluation in FMEA. Engineering Failure Analysis, v. 18, n. 4, p. 1162-1170, Jun. 2011.

YIN, R. K. Estudo de caso: planejamento e métodos. Porto Alegre : Brookman, 2001.

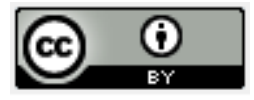

Artigo recebido em 28/04/2010 e aceito para publicação em 10/10/2011. 